International Journal of MCH and AIDS (2018), Volume 7, Issue I, 38-46

\begin{tabular}{ll}
\hline & INTERNATIONAL JOURNAL \\
& of MCH and AIDS \\
ISSN 216I-864X (Online) & ISSN 216I-8674 (Print) \\
& DOI: I0.2 I I06/ijma.248 \\
\hline
\end{tabular}

\title{
ORIGINALARTICLE
}

\section{Individual and Household Risk Factors for Severe Acute Malnutrition among Under-Five Children in the Analamanga Region, Madagascar}

\author{
David Rakotonandrasana Harimbola, $\mathrm{PhD}, \mathrm{MD}{ }^{\mid ⿴ 囗 十 ~ K a o r i ~ M i z u m o t o, ~} \mathrm{PhD}^{2}$ \\ 'Centre Hospitalier Universitaire Antananarivo, Hôpital Mère Enfant Ambohimiandra, Service de Pédiatrie, Ambohimiandra-Antananarivo I0I, \\ MADAGASCAR; ${ }^{2}$ Department of Nutrition Sciences, Nakamura Gakuen University, Fukuoka, JAPAN \\ Corresponding author email: rakotohar@yahoo.fr
}

\section{ABSTRACT}

Background and Objectives: Despite some progress made in the fight against malnutrition in Madagascar, hospitals' mortality due to severe acute malnutrition (SAM) remains high. This study explores the risk factors for SAM among children hospitalized with SAM in the Analamanga region of Madagascar.

Methods:We conducted an interview based qualitative study of 14 mothers of under-five children with SAM admitted to the hospital's pediatric unit and living in the Analamanga region. Data were analyzed using thematic analysis method.

Results: There were direct, intermediate and basic causes of malnutrition shared with other health care settings. Low health literacy such as limited knowledge and optimistic perception of malnutrition, and lack of health service information resulted in delayed hospital visit for care of SAM.Vulnerable working mothers do not benefit from available community support structure. Mothers are unable to practice what they learned because financial difficulties at the household level occupy their time.

Conclusions and Global Health implications: Consideration of vulnerable working mothers' access to existing health services and interventions to address health literacy are important to prevent SAM at the community level. Study findings would be of interest to practitioners and policy makers in the region and perhaps in other resource limited settings.

Key words: Severe Acute Malnutrition (SAM), • Health Literacy • Utilization of Health Services • Working Mothers $\cdot$ Madagascar

Copyright (C) 2018 Harimbola and Mizumoto. This is an open-access article distributed under the terms of the Creative Commons Attribution License, which permits unrestricted use, distribution, and reproduction in any medium, provided the original work is properly cited.

\section{Introduction}

Child undernutrition has severe implications for child survival, health, and skills development throughout the course of life. It has been estimated that almost half of all deaths of children under five years of age are due to undernutrition.' The loss of human capital resulting from undernutrition in childhood, reflected in poorer health, cognitive and socioemotional development, and schooling outcomes leads to lower economic productivity and economic status in adulthood, and is estimated 
to reduce a nation's economic advancement by at least eight percent. ${ }^{2}$

\section{I.I Background of the Study}

Undernutrition in the aggregate was the cause of 3.1 million child deaths annually or $45 \%$ of all child deaths in 201 I.' Between 1990 and 2016, a tangible decrease globally in child stunting prevalence, from $39.6 \%$ to $22.9 \%$, was observed. For 2016 , it was estimated that 52 million under-five children were globally wasted, of which 17 million were severely wasted. ${ }^{3}$ Although the decrease in wasting was not precisely determined due to limited data sources and the difficulty to establish a reliable trend over time due to its rapid and frequent change, ${ }^{4,5}$ the rate of wasting steadily increased in 51 out of 126 countries between 2012 and $2014 .{ }^{6}$ Severely wasted children with a weight-forheight below minus 3 standard deviations (SDs) based on World Health Organization (WHO) standards, i.e., experiencing severe acute malnutrition (SAM), have a higher risk of death (>nine-fold) compared to children with a weight-for-height above minus I SD. ${ }^{7}$

WHO guideline for inpatient treatment of severely malnourished children indicates that the mortality rate should not exceed $10 \%$ if treatment is followed correctly. ${ }^{8}$ Studies of sub-Saharan Africa countries reported varying levels of inpatient mortality rates by SAM, from less than $10 \%$ to more than $40 \%$, despite health centers compliance with $\mathrm{WHO}$ guidelines. ${ }^{9}$ In Madagascar, according to data from the Ministry of Health, there was a progressive decrease in the proportion of malnourished children through successive years, from 13\% in 2009 to $9 \%$ in $2013 .^{10}$ Despite this progress and the existence of well-defined policies and programs to combat malnutrition, the latest data published in 2014 showed that undernutrition is still a major problem in Madagascar." Amongst I,704,684 children seen in primary health care for their nutritional status, I34,623 (7.9\%) were moderately malnourished and another 29, I39 (I.7\%) were severely malnourished. The mortality rate of severe acute undernutrition remains high at tertiary hospitals in Madagascar. ${ }^{10}$

\section{I.2 Objectives of the Study}

This study explores the underlying individual and household risk factors for SAM among hospitalized children with SAM in the Analamanga region of Madagascar. The information from this study may be important in preventing increase in the prevalence of malnutrition among under-five children that could potentially lead to hospitalizations.

\section{Methods}

A qualitative study was performed in the pediatric unit of the Hôpital Mère-Enfant Ambohimiandra, Centre Hospitalier Universitaire Antananarivo, Madagascar, between November 2013 and January 2015. The hospital is the only "Mother and Child Hospital" among the seven University hospitals in the city of Antananarivo. Patients at the hospital are mainly from the city itself and from different towns and rural areas of the six districts forming the Analamanga region. The hospital receives around I,000 child inpatients annually at the pediatric unit, and approximately $10 \%$ of those children suffer from SAM. The non-SAM mortality rate in the unit is around $7 \%$. Meanwhile, the SAM mortality rate is four-fold greater than the non-SAM mortality rate, according to our inpatient records.

\section{I Study Participants}

The study subjects were under-five children admitted to the pediatric unit in the hospital with SAM and their mothers. In this study, we use the word "mother" to designate biological or non-biological mothers living in the Analamanga region, including Antananarivo City, Antananarivo Avaradrano, Antananarivo Atsimondrano, Ambohidratrimo, Andramasina, and Manjakandrina. SAM diagnosis was based on WHO criteria; ${ }^{12}$ potential study participants included children who survived more than 24 hours after admission and their mothers. Due to ethical considerations, children that survived for more than 24 hours after admission but remained in critical condition were excluded from the study.

\subsection{Data Collection and preparation}

Face-to-face in-depth interviews with the mothers were performed by the principal investigator following the interview guide based on the United Nations International Children's Emergency Fund (UNICEF) framework of malnutrition. ${ }^{13}$ Although some weaknesses of the UNICEF had been reported such 
as difficulties to establish clear connections between inputs, outputs, outcomes and impact, ${ }^{13}$ we decided to employ the framework since it seemed to enable us at least identify issues we should focus on in the study area. Interviews were conducted with the mothers alone except in one case when the father asked permission to assist his wife for the interview. The study was explained to potential participants and their consent to participate in the study was obtained. Interviews were conducted mostly between the second and fifth day of hospitalization, when the child was stabilized. Fourteen interviews were performed. Each interview took approximately 30 to 60 minutes, and the child's birth weight, growth, and immunization records were checked from their child health handbook. The investigators agreed to "data saturation"14 of the sample size for the current study and performed data analysis. All interviews conducted in local language by the first author (DRH) were audiotaped and transcribed then translated to English. (Figure I.)

\subsection{Data Analysis}

Data analysis took place according to the thematic analysis method. ${ }^{15,16} \mathrm{DRH}$ and KM participated equally in the data analysis. Each analysis by one investigator was cross-checked by the other and vice-versa. Any disagreement between authors in each step of the analysis was discussed until consensus was reached. First, contextual text segmentations were obtained from the translated transcriptions. The text segments were open-coded initially, and the codes were grouped into similar concepts. Subsequently, concepts were thematically coded and grouped into categories. We decided to use the UNICEF framework of malnutrition again for the theoretical framework of the current study since connections between variables following the framework were emerging at the cording stage. The procedure was performed manually. The research proposal was approved on October 28, 2014 by the Ethical Committee of Hôpital Mère Enfant Ambohimiandra.

\section{Results}

\section{I Sociodemographic characteristics of the mother-participants}

Table I shows the sociodemographic characteristics of the mothers. All were mothers (mean age, 27 \pm 7.2 years), with the majority being 20-29 years old $(57.1 \%)$. While younger mothers aged less than 30 years had just one or two children, older mothers tended to have more children. Most of the mothers

Table I: Socio-demographic characteristics of the subjects (mothers)

\begin{tabular}{|c|c|c|c|c|c|}
\hline Variables & $n=14$ & $(\%)$ & Variables & $n=14$ & (\%) \\
\hline & & & Number of children & & \\
\hline \multirow[t]{3}{*}{ Mother } & 14 & $(100.0)$ & $\mathrm{I}-2$ & 9 & $(64.3)$ \\
\hline & & & $3-4$ & 2 & $(14.3)$ \\
\hline & & & $>4$ & 3 & $(21.4)$ \\
\hline Age group & & & Occupation & & \\
\hline$<20$ years & I & $(7.1)$ & No occupation* & 2 & $(14.3)$ \\
\hline $20-29$ & 8 & $(57.1)$ & Agriculture & 2 & $(14.3)$ \\
\hline $30-39$ & 4 & $(28.6)$ & Employed-government $\dagger$ & 2 & $(14.3)$ \\
\hline \multirow[t]{2}{*}{$40-49$} & I & $(7.1)$ & Self-employed $\ddagger$ & 7 & $(50.0)$ \\
\hline & & & Student & $\mathrm{I}$ & $(7.1)$ \\
\hline \multicolumn{6}{|l|}{ Marital status } \\
\hline Married & 11 & $(78.6)$ & & & \\
\hline Unmarried & 1 & $(7.1)$ & & & \\
\hline Divorced & $\mathrm{I}$ & $(7.1)$ & & & \\
\hline Widow & I & $(7.1)$ & & & \\
\hline
\end{tabular}




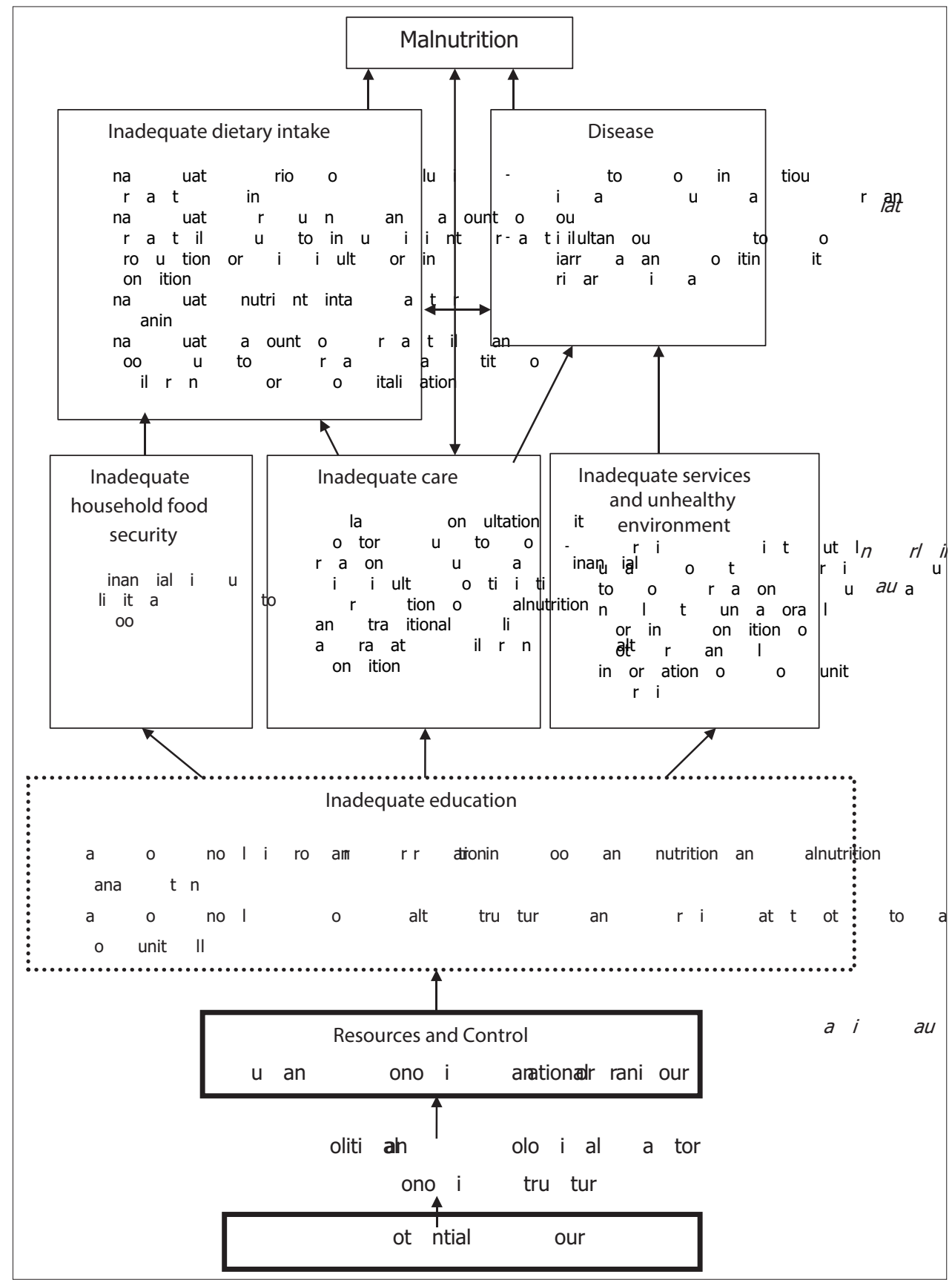

Figure I: Causes of child malnutrition

were self-employed; their primary occupations included food and commodity sales, housekeeping (e.g., washing clothes), and cooking. (Table I.)

\subsection{Nutritional status of the child-participants}

Table 2 presents basic information and the nutritional status of the children (age, 7-16 months; 
mean age, II \pm 2.6 months). There were two children whose height for age Z-score fell into the range of -2 ; the rest were categorized as -3 . As for the weight Z-score for age and body mass index (BMI) Z-score, all children fell into the range of -3 . (Table 2.)

\subsection{Potential Immediate causes of child undernutrition}

\subsection{Inadequate dietary intake}

Based on thematic analysis of mothers' remarks related to dietary intake, we identified four major themes: I) Inadequate period of exclusive breastfeeding, 2) Inadequate frequency and amount of breastmilk due to insufficient breastmilk production or difficult working conditions militating against breastfeeding, 3) Inadequate nutrient intake after weaning, and 4) Inadequate amount of breastmilk and food due to decreased appetite of children before hospitalization.

There was only one child who was exclusively breastfed until the age of 6 months. On the other hand, all children were in the recommended period to be fed with breastmilk. Regarding frequency and amount of breastmilk, about half of the mothers were not able to produce sufficient breastmilk or had difficult working conditions to provide breastmilk frequently. Alternatives for breastmilk were mostly commercially available plain cow milk or condensed milk. One mother mentioned the use of sugar water as an alternative. The mother's description of the food they gave to their children showed some degree of diversification; however, protein-rich foods were not sufficient for most of the children. Only one mother was providing her children with various protein-rich foods in each meal. The children were generally fed three times a day with breastmilk or alternatives. Although the frequency of the meals was appropriate, about half of the mothers reported a small appetite in their children. Prior to hospital admission, many mothers noticed a decreased appetite in their children.

\subsubsection{Diseases}

Diseases are often important direct causes of malnutrition. In the current study, we identified I) Symptoms of infectious diseases such as fever and cough and 2) Simultaneous symptoms of diarrhea and vomiting with primary diseases, as diseases-related themes.

The majority of children had fever and respiratory warning signs, such as cough and coryza few days before hospital admission. Most of mothers mentioned that their children had diarrhea and/or vomiting before hospitalization.

\subsection{Underlying causes of child undernutrition}

\subsection{Inadequate access to food}

Economic status determines the ability to obtain food. We identified a theme under this category: financial issues limit access to food. Some mothers declared that they were having serious financial issues. One mother said that she withdrew the oldest (eight years old) of her children from school and sent him to work to help the family. Some of her other children simply stopped

Table 2: Nutritional status of the subjects (children)

\begin{tabular}{|c|c|c|c|c|c|}
\hline Variables & $n=14$ & (\%) & Variables & $n=14$ & (\%) \\
\hline Age & & & Ht Z score for age & $\mathrm{n}=14$ & \\
\hline $7-10$ months & 6 & $(42.9)$ & -2 & 2 & $(14.3)$ \\
\hline $11-16$ months & 8 & $(57.1)$ & -3 & 12 & $(85.7)$ \\
\hline Sex & & & Wt Z score for age & $\mathrm{n}=14$ & (\%) \\
\hline Male & 9 & $(64.3)$ & -3 & 14 & $(100.0)$ \\
\hline Female & 5 & $(35.7)$ & & & \\
\hline Weight at birth (g) & & & BMI Z score for age & $\mathrm{n}=14$ & (\%) \\
\hline$<2500 \mathrm{~g}$ & 2 & $(14.3)$ & -3 & 14 & $(100.0)$ \\
\hline$>2500 \mathrm{~g}$ & 10 & (7I.4) & & & \\
\hline unknown & 2 & $(14.3)$ & & & \\
\hline
\end{tabular}


attending school due to cost limitations. The same mother affirmed that she should have also postponed seeking care due to a lack of money. Four mothers amongst those interviewed were single mothers. Although fathers were present in the households, the majority were in unstable employments or regular work with low salaries. Most mothers said that their earnings were not sufficient to purchase food. One mother said that "there is at least some rice to eat."

\subsubsection{Inadequate care for children and mothers}

Care-seeking behavior touches on either control or aggravation of health problems. The major theme that could be peculiar in the study area we identified was: delayed consultation with doctors due to some reasons (such as financial difficulty, optimistic perception of malnutrition and traditional beliefs) aggravates children's health conditions. The majority of mothers delayed going to hospital and consequently, the health conditions of their children became worse. Many mothers tried first to treat fever and cough at home with medications available from pharmacies in town. Some mothers were busy with work and did not seek medical attention in a timely fashion after recognizing the child's illness. One said her family was reluctant to take the child to the hospital due to financial difficulties. Many mothers believed that being underweight was not a serious health problem, and some believed that their children were healthy despite being underweight. Some mothers also believed that teething caused diarrhea and illness, which resulted in delayed medical treatment. Most mothers did not believe that their child's illness was associated with witchcraft; however, two mothers consulted with traditional healers before seeing a doctor.

\subsubsection{Inadequate health services and an unhealthy environment}

The theme related to health services and environmental issues we identified was: services exist but less usage of the services due to some reasons such as neglect, unfavorable working condition of mothers, and limited information on available community services. Half of mothers indicated that their children had received immunizations and were weighed on a regular basis. Some missed immunizations due to apparent neglect or the mother's working condition. Growth monitoring is commonly performed at the health center, but many mothers tended not to actively pay attention to growth patterns. Most mothers mentioned that there was no help from the community, and many of them had never received support from health volunteers. At the same time, most of them mentioned that they did not know about the existence of services available in the communities.

\subsection{Inadequate education}

We identified the following two themes under this category: I) Lack of knowledge and improper perception regarding food and nutrition and malnutrition management, and 2) Lack of knowledge of health structures and services devoted to malnutrition management at the community level. The majority of mothers discussed their experiences related to the importance of breastfeeding. Importance of colostrum, and duration of exclusive breastfeeding were well-known amongst the mothers. However, knowledge of food and nutrition was limited. Some mothers mentioned that they did not know what types of food were suitable for children. The mothers tended not to be concerned about the nutritional quality of food and many of them did not worry about malnutrition since they believed that malnutrition is not a sickness. Although the mothers had no clear concept of the relationship between malnutrition and diarrhea, they considered diarrhea as a health problem that should be treated. One of the mothers who had completed secondary school said that she had learnt health and nutrition at school. Most mothers dropped out of school after a few years in primary school or continued further but did not complete secondary school. Although the mothers had some knowledge of specific topics, low health literacy associated with general nutrition was observed from the interviews. Many mothers did not understand the health structure and services devoted to malnutrition management at the hospital and at the community level. One mother said that she did not understand how health services worked and relied on her own observations to monitor her child's health.

\section{Discussion}

We summarized the findings of the current study into the UNICEF framework of child malnutrition 
(Figure I). Statements in each category of the framework are qualitative themes that we identified from remarks of the study subjects. Prior to leading conclusion, we will try to identify possible connections between the themes for better understanding of the entire situation of child malnutrition in the study area.

The hospitalized children with SAM in the current study showed several symptoms of infectious diseases such as fever and cough. Diarrhea and vomiting were also often observed simultaneously. Fever and cough consume extra energy of children and diarrhea and vomiting disturb energy and nutrient intake. Those symptoms cause weight loss easily and also affect appetite of the children. In this study, even before hospital admission, many mothers noticed decreased appetite in their children. It probably may have caused small intake of breastmilk and food in the children. However, most mothers took time to decide about going to the hospital, while children's health conditions consequently worsened. When those children arrived at the hospital, the illness had been aggravated with severe weight loss. With mild symptoms of diarrhea, mothers tended to "wait and watch." The optimistic perception of malnutrition was common amongst all the mothers. It often delayed hospital visits. Some mothers believed that teething caused diarrhea and illness, which also delayed seeking medical treatment for their children.

Inadequate dietary intake was not only led by decreased appetite due to illness but also by some reasons attributed to their mothers and families. We observed inadequate dietary intake on a daily basis formed precondition of SAM. A study in Bangladesh reported that SAM and severe chronic malnutrition (SCM) co-exist. ${ }^{17}$ In the current study, severe or even moderate chronic malnutrition due to inadequate dietary intake was associated with SAM.The majority of children were not receiving sufficient breastmilk. Previous studies indicated a significant relationship between knowledge and breastfeeding practice. ${ }^{8-20}$ The importance of breastfeeding was well-known amongst the subjects and they continued breastfeeding. However, the issue of breastfeeding in our study was not merely its continuation but in addition the frequency and amount of breastmilk. A recent study reported that a mother's working condition is a significant factor in breastfeeding practice. ${ }^{21}$ Some of our subjects also mentioned about difficult working conditions to continue frequent breastfeeding. The latest political turmoil of 2009 deteriorated significantly the national economy with impacts in each household making $92 \%$ of the population to live under the poverty line. ${ }^{22,23}$ Such widespread poverty made many mothers to keep working in order to increase their household income just for their family survival. Measures to increase frequency of breastfeeding for working mothers should be considered in response to child malnutrition. On the other hand, providing proper knowledge on good practices around breastfeeding and weaning would help to reduce child malnutrition in the study area.

Regarding underlying causes of malnutrition, we focus on modifiable findings. We recognized the finding under inadequate care. Delayed consultation with doctors due to some reasons such as optimistic perception of malnutrition and traditional beliefs was certainly connected to findings under inadequate dietary intake and diseases. Findings from inadequate education such as lack of knowledge and improper perception of malnutrition management and also health structures and services were the bases of other findings as underlying causes.

Many mothers discussed the lack of support from their community. However, consultation services for health and nutrition were available at the community level in Madagascar. Some service providers said that young mothers were not proactive in accessing such services. Most young mothers in the study were focused on making money for their living, and had little time to partake in community activities. Public supports exist in communities but the supports were not fully utilized especially by working mothers. Published mortality rates in Asia tend to be lower compared to those of Sub-Saharan Africa, suggesting healthcare organizations in Asia may play a role in addressing child mortality. ${ }^{24}$ Although the organizational structure of healthcare services may not be mature enough in many Sub-Saharan African countries, minimal services are available. If the service utilization by working mothers is increased in the study area, the situation of child malnutrition could be improved. Nevertheless, financial difficulty at the 
household level often occupies the mothers' time and limits involvement in community activities. As well as the issue of breastfeeding mentioned earlier, "working mothers" is a keyword here. In order to increase health service utilization, efforts to mobilize working mothers in community activities should be considered.

Potential pathways to SAM in this study were similar to previous studies ever reported, although combinations of underlying factors to SAM depended on study areas. Delayed consultation with doctors seemed the most critical factor of aggravating malnutrition status. Our findings suggest that health literacy such as malnutrition-related knowledge and perception and also information on available health services should be enhanced. It is important to consider working mothers' situation both in the process of health literacy enhancement and practices based on enhancing health literacy. Further studies are needed to explore effective and acceptable approaches for child malnutrition management for working mothers in this study area. Preventing aggravation of SAM at hospitals should begin before hospital admission.

\section{Conclusions and Global Health Implications}

We observed that low health literacy of the mothers in the study areas resulted in delay in hospital visit for their child's treatment for malnutrition while malnutrition worsened. Preventing SAM at hospitals should begin before hospital admission by addressing low health literacy among mothers. Although healthrelated information were available at community level, mothers with financial difficulty tended not to access such information and their health service utilization was low. Our findings indicate the importance of considering working mothers' access to existing health services with enhancement of health literacy to prevent SAM at community level. Study findings may be of benefit to not only communities in the study area but also in other areas in Madagascar and potentially in other resource- limited settings across the worldwide.

\section{Compliance with Ethical Standards}

Conflicts of Interest: The authors declare no conflicts of interest associated with this study. Financial Disclosure: None. Funding/Support: None.

\section{Key Messages}

Severe Acute Malnutrition (SAM) among under-five children in Madagascar is the product of multiple individual and household risk factors that put the lives of children at risk.

- Addressing the many barriers to seeking help, increasing awareness of exiting community resources, and services amenable to schedules that allow working mothers opportunity to seek out these services could potentially assist in addressing the mortality due to SAM among children in Madagascar.

Improving health literacy among mothers may contribute in addressing the risk factors for SAM at the community level.

Ethics Approval: The research proposal was approved by approved ethical committee. Acknowledgements: The authors are grateful to the Director of the Hôpital Mère Enfant Ambohimiandra, Dr. Ravelomanana Lovaniaina, without whose permission this research will not be possible. The authors also acknowledge the pediatric unit and all the hospital staff for their valuable assistance during the data collection, and all mothers for their participation.

\section{References}

I. Black RE, Victora CG,Walker SP, et. al. Maternal and child undernutrition and overweight in low-income and middle-income countries: Maternal and Child Nutrition Study Group. Lancet. 2013; 9890: 427-45I.

2. Horton S, Steckel R. Global economic losses attributable to malnutrition 1990-2000 and projections to 2050. In: Lomborg B, ed. How Much Have Global Problems Cost The World? Cambridge: Cambridge University Press; 2013.

3. Joint child malnutrition estimates 2017 (UNICEFWHO-WB). http://datatopics.world bank.org/childmalnutrition/.Accessed April 29, 2018.

4. UNICEF-WHO-World Bank Group, Levels and Trends in Child Mortality Report 2014. http:// www.unicef.org/media/files/Levels_and_Trends_in_ Child_Mortality_2014.pdf.Accessed April 29, 2018.

5. Levels and trends in child Malnutrition. UNICEF/ WHO/World Bank Group Joint Child Malnutrition Estimates. Key findings of the 2017 edition. http:// www.who.int/nutgrowthdb/jme_brochoure2017.pdf 
Accessed April 29, 2018.

6. International Food Policy Research Institute. Global Nutrition Report:Actions and Accountability to Accelerate the World's Progress on Nutrition. Washington DC: International Food Policy Research Institute; 20l4. http://dx.doi.org/l0.2499/978089 6295643. Accessed April 29, 2018.

7. WHO and UNICEF, WHO child growth standards and the identification of severe acute malnutrition in infants and children, Geneva: WHO, 2009. http://apps.who.int/iris/ bitstream/I0665/44 I29/I/978924 I598I63_eng.pdf. Accessed April 29, 2018.

8. Ashworth A, Khanum S, Jackson A, et al. Guidelines for the inpatient treatment of severely malnourished children. Geneva: World Health Organization; 2003. http://www.who.int/nutrition/publications/guide_ in patient_text.pdf.Accessed April 29, 2018.

9. Nhampossa T, Sigaúque B, Machevo S, et al. Clara Menéndez, Victoria Fumadó. Severe malnutrition amongst children under the age of 5 years admitted to a rural district hospital in southern Mozambique. Public Health Nutrition. 2013; 16(9): I565-I574. doi: $10.1017 / S \mid 368980013001080$

10. Ministère de la Santé Madagascar, Annuaire des Statistiques du Secteur Santé Madagascar 200920I3. http://instat.mg/sante/annuaire-statistiquedu-secteur-sante-de-madagascar-1999-a-2013/. Accessed April 29, 2018.

II. Ministère de la Santé Madagascar, Protocole National de Prise en Charge de la Malnutrition Aiguë.Antananarivo; Ministère de la Santé; 2013.

12. World Health Organization, Guideline: Update on the management of severe acute malnutrition in infants and children. Geneva: World Health Organization, 2009. http://apps.who.int/iris/ bitstream//0665/95584/I/978924 I506328_eng.pdf. Accessed April 29, 2018.

13. United Nations Children's Fund, Strategy for improved nutrition of children and women in developing countries, New York, NY, USA: UNICEF 1992. http://ceecis.org/iodine/0I_global/0I_ pl/0I_0I_other_1992_unicef.pdf Accessed April 29, 2018.
14. Bernard HR. Social Research Methods. Thousand Oaks: Sage; 2000.

15. Glaser BG, Strauss AL. The Discovery of Grounded Theory: Strategies for Qualitative Research. Chicago: Aldine De Gruyter; 1967.

16. Patton MQ. Qualitative Research and Evaluation Methods. Thousand Oaks: Sage; 2001.

17. Shams Z, Zachariah R, Enarson DA, et al. Severe malnutrition in children presenting to health facilities in an urban slum in Bangladesh, Public Health Action. 2012;2(4): 107-III.

18. Cherop CE, Keverenge-Ettyang AG, Mbagaya GM, Barriers to exclusive breastfeeding amongst infants aged 0-6 months in Eldoret municipality, Kenya. East African Journal of Public Health. 2009; 6(I): 69-72.

19. Kishore MS, Kumar P, Aggarwal AK. Breastfeeding Knowledge and Practices amongst Mothers in a Rural Population of North India:A Community-based Study. Journal of Tropical Pediatrics. 2009; 55: 183-8.

20. Tyndall JA, Kamai R, Changchangi D, Knowledge, Attitudes and Practices on Exclusive Breastfeeding in Adamawa, Nigeria. American Journal of Public Health Research. 2016; 4(3): I12-119.

21. Khaliq A, Qamar M, Hussaini SA, et al. Assessment of knowledge and practices about breastfeeding and weaning amongst working and non-working mothers, Journal of the Pakistan Medical Association. 2017; 67(3): 332-338.

22. Madagascar: Measuring the Impact of the Political Crisis. The World Bank, June 2013 http://www. worldbank.org/en/news/feature/2013/06/05/ madagascar-measuring-the-impact-of-the-politicalcrisis. Accessed April 29, 2018.

23. International Monetary Fund. Republic of Madagascar Economic Development Document IMF Country Report No, I7/225. July 2017. http:// www.imf.org/en/Publications/CR/lssues/2017/07//8/ Republic-of-Madagascar-Economic-DevelopmentDocument-45099 Accessed April 29, 2018.

24. Sanghvi J, Mehta S, Kumar R. Predicators for weight gain in children treated for severe acute malnutrition: a prospective study at nutritional rehabilitation center. International Scholarly Research Network Pediatrics. 20I4; 20I4: I-5. 